taking additional valproate, all recovered when the carbamazepine dose alone was reduced. The remaining two patients who became toxic were initially taking only carbamazepine. The main importance of the interaction arises from the tendency for tuberculosis to occur in long-term hospitals that may have a large epileptic population. Whenever the two drugs are prescribed simultaneously close monitoring of carbamazepine concentrations is indicated.

We thank Dr G W Hearn and Dr C Skinner for their help and permission to report on patients under their care.

1 Park BK, Breckenridge AM. Clinical implications of enzyme induction and enzyme inhibition. Clin Pharmacokinet 1981;6:1-24.

${ }^{2}$ Kutt H, Brennan R, Dehejia H, Verebely K. Diphenylhydantoin intoxication. A complication of isoniazid therapy. Am Rev Respir Dis 1970; 101:377-84.

${ }^{3}$ Eichelbaum M, Erbom K, Bertilsson L, Ringberger V, Rane A. Plasma kinetics of carbamazepine and its epoxide metabolite in man during single and multiple dosing. Eur f Clin Pharmacol 1975;8:337-41.

${ }^{4}$ Brennan RW, Dehejia H, Kutt H, McDowell F. Diphenylhydantoin intoxication attendant to slow inactivation of isoniazid. Neurology (Minneap) 1968;18:283-7.

${ }^{5}$ Schneider H. Carbamazepine: an attempt to correlate serum levels with anti-epileptic and side effects. In: Schneider H, ed. Clinical pharmacology of anti-epileptic drugs. Berlin: Springer Verlag, 1975:151-8.

(Accepted 12 May 1982)

Chelmsley Hospital, Marston Green, Birmingham B37 7HL

V C VALSALAN, MB, DPM, consultant psychiatrist

Ciba-Geigy Pharmaceuticals Division, Horsham, West Sussex RH12 4AB

G L COOPER, MB, MRCGP, medical adviser

\section{Insulin resistance and hypomagnesaemia: case report}

Magnesium is essential for many enzyme systems, especially those utilising high-energy phosphate bonds. ${ }^{1}$ Though its importance to normal cellular function is increasingly acknowledged, the potential loss occurring during severe diabetic ketoacidosis ${ }^{2}$ is often ignored. We present a case illustrating the benefit of replacing this essential ion.

\section{Case report}

A 34-year-old type I diabetic woman who had been well controlled for 20 years with 42 units isophane insulin daily was admitted in severe ketoacidosis precipitated by a urinary tract infection. Treatment was instituted with intravenous fluids supplemented with potassium, intravenous antibiotics, and intramuscular insulin according to the Alberti regimen. Initial response was good, resulting in a rapid fall in the plasma glucose concentration with electrolyte values and acid-base balance returning to normal within 48 hours. This was achieved with a diet of $120 \mathrm{~g}$ carbohydrate and 64 and 60 units insulin being given during the first and second 24-hour periods.

Within three days the plasma glucose concentration had become increasingly difficult to control and there was a profound deterioration in the patient's clinical condition, with anorexia, nausea, and vomiting indicating the return of ketoacidosis. The urinary tract infection was responding well, but despite increasing the dose of Actrapid MC from 50 to 100 units in 24 hours she showed no improvement. The plasma magnesium concentration was e. imated, and as this was $0.67 \mathrm{mmol} / 1(1.6 \mathrm{mg} / 100 \mathrm{ml}$ ) (normal range $0 \cdot 80.1 .04 \mathrm{mmol} / 1 ; 1 \cdot 9-2.5 \mathrm{mg} / 100 \mathrm{ml}) 60 \mathrm{mmol}$ magnesium sulphate was given intravenously over six hours and oral treatment begun. The insulin requirement fell rapidly to 44 units daily and she showed a remarkable improvement, the acid-base balance again returning to normal (figure).

\section{Comment}

The neurological manifestation of hypomagnesaemia may vary from tetany or muscle weakness to depression or frank psychosis, while the cardiac manifestations are those of electrocardiographic and rhythm changes. A previously reported case ${ }^{3}$ of asystole associated with hypomagnesaemia during diabetic ketoacidosis illustrated the benefit that magnesium replacement may bring. It has been pointed out ${ }^{4}$ that the loss of magnesium during the treatment of diabetic ketosis follows the same pattern as potassium loss, and it has been suggested that magnesium should be added to intravenous fluids in a concentration of $5 \frac{\Phi}{2}$ mmol.

In our patient initial control of the diabetic ketosis was easily achieved, and it was only when stabilisation would normally have been $\cong$ expected that difficulties in control arose. Though an anti-insulin hormonal response precipitated by increasing ketosis or the urinary tract ${ }_{\mathbb{D}}^{D}$ infection may have been responsible for the increasing insulin require-ments, we think that magnesium deficiency was more likely, especially in view of the dramatic response to the magnesium infusion. While we.

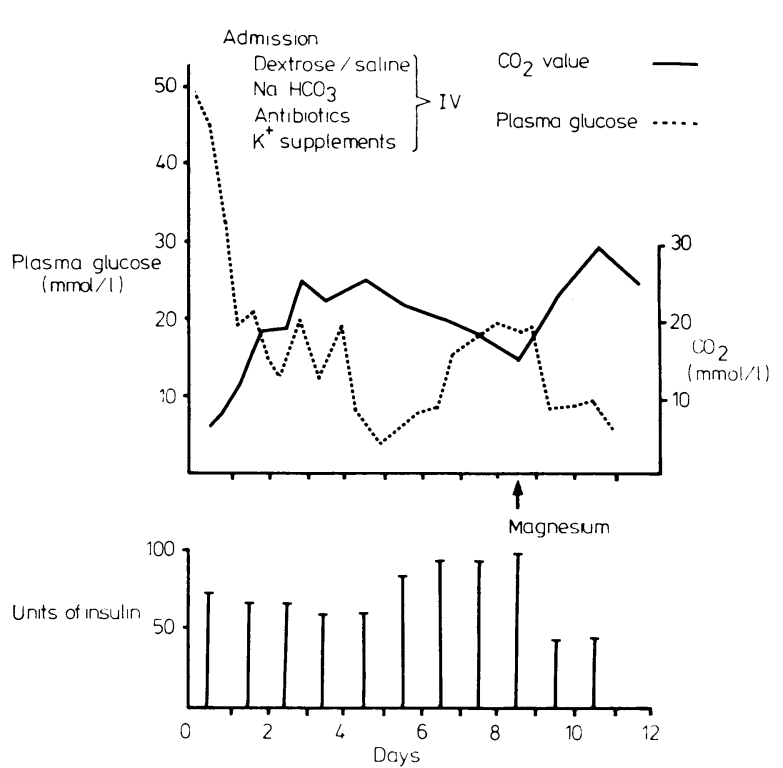

Effect of intravenous magnesium sulphate on insulin requirement and plasma glucose and carbon dioxide concentrations.

Conversion: SI to traditional units-Plasma glucose: $1 \mathrm{mmol} / 1$

$\approx 18 \mathrm{mg} / 100 \mathrm{ml}$. Carbon dioxide: $1 \mathrm{mmol} / 1 \approx 4 \cdot 4 \mathrm{mg} / 100 \mathrm{ml}$.

accept that the administration of magnesium sulphate in $500 \mathrm{ml}$ $5 \%$ dextrose might have caused some plasma expansion thereby응 decreasing the insulin requirements, we think that this decrease was so pronounced as to merit some other mechanism. This mechanism may have been the improvement of enzyme systems through which insulin: must eventually function. The rapid response to magnesium replacement has been noted by others. ${ }^{35}$

We suggest that the possibility of magnesium depletion should be borne in mind more often, especially when diabetic ketoacidosis proves 3 difficult to control. Replacement is easily achieved with $60-80 \mathrm{mmol}$. magnesium sulphate given intravenously over four to six hours followed by $10 \mathrm{ml}$ magnesium chloride ( $20 \%$ solution) twice daily. With children or those with a light body build the dose is 0.5 to $1.0 \mathrm{mmol} / \mathrm{kg}$ body 을 weight.

We thank Dr A P Grant for permission to publish the details of this patient, $\frac{D}{O}$ who was under his care.

1 Wacker WEC, Parisi AF. Magnesium metabolism. N Engl f Med 1978; N 278:658-63.

2 Martin HE, Smith K, Wilson ML. The fluid and electrolyte therapy of severe diabetic acidosis and ketosis. Am $\mathcal{F}$ Med 1958;24:376-89.

3 McMullen JK. Asystole and hypomagnesaemia during recovery from diabetic ketoacidosis. Br Med $\mathcal{F}$ 1977; i:690.

4 Miller H, Daley H. Progress in clinical medicine. Edinburgh: Churchill Livingstone, 1971:301-5.

${ }^{5}$ Harris I, Wilkinson AW. Magnesium depletion in children. Lancet $1971 ; \frac{\text { }}{\mathbb{Q}}$ ii :735-6.

(Accepted 11 May 1982)

Cardiac Unit, Belfast City Hospital, Belfast BT9 7AB

KENNETH $W$ MOLES, MB, MRCP, senior registrar

J KENNETH MCMULLEN, MB, MRCP, senior registrar 